\title{
Article \\ Cryptic Diversity in Cladosporium cladosporioides Resulting from Sequence-Based Species Delimitation Analyses
}

\author{
Andrea Becchimanzi ${ }^{1}\left(\mathbb{D}\right.$, Beata Zimowska $^{2, *(D)}$ and Rosario Nicoletti ${ }^{1,3}$ (D) $^{-}$ \\ 1 Department of Agricultural Sciences, University of Naples Federico II, 80055 Portici, Italy; \\ andrea.becchimanzi@unina.it (A.B.); rosario.nicoletti@crea.gov.it (R.N.) \\ 2 Department of Plant Protection, University of Life Sciences, 20-069 Lublin, Poland \\ 3 Council for Agricultural Research and Economics, Research Centre for Olive, Fruit and Citrus Crops, \\ 81100 Caserta, Italy \\ * Correspondence: beata.zimowska@up.lublin.pl
}

Citation: Becchimanzi, A.;

Zimowska, B.; Nicoletti, R. Cryptic

Diversity in Cladosporium

cladosporioides Resulting from

Sequence-Based Species Delimitation Analyses. Pathogens 2021, 10, 1167.

https://doi.org/10.3390/

pathogens 10091167

Academic Editor: Nemat O. Keyhani

Received: 2 August 2021

Accepted: 8 September 2021

Published: 10 September 2021

Publisher's Note: MDPI stays neutral with regard to jurisdictional claims in published maps and institutional affiliations.

Copyright: (c) 2021 by the authors. Licensee MDPI, Basel, Switzerland. This article is an open access article distributed under the terms and conditions of the Creative Commons Attribution (CC BY) license (https:// creativecommons.org/licenses/by/ $4.0 /)$.

\begin{abstract}
Cladosporium cladosporioides is an extremely widespread fungus involved in associations ranging from mutualistic to pathogenic and is the most frequently represented Cladosporium species in sequence databases, such as Genbank. The taxonomy of Cladosporium species, currently based on the integration of molecular data with morphological and cultural characters, is in frequent need of revision. Hence, the recently developed species delimitation methods can be helpful to explore cryptic diversity in this genus. Considering a previous study that reported several hypothetical species within C. cladosporioides, we tested four methods of species delimitation using the combined DNA barcodes internal transcribed spacers, translation elongation factor $1-\alpha$ and actin 1 . The analyses involved 105 isolates, revealing that currently available sequences of C. cladosporioides in GenBank actually represent more than one species. Moreover, we found that eight isolates from this set should be ascribed to Cladosporium anthropophilum. Our results revealed a certain degree of discordance among species delimitation methods, which can be efficiently treated using conservative approaches in order to minimize the risk of considering false positives.
\end{abstract}

Keywords: Cladosporium; cryptic species; phylogenetic analysis; species delimitation methods; taxonomic markers

\section{Introduction}

Fungi belonging to the genus Cladosporium (Dothideomycetes, Cladosporiaceae) are ubiquitous in connection with their ability to colonize any kind of organic substrate in both terrestrial and marine environments [1]. With their branched chains of small conidia, which are easily spread over long distances, Cladosporium species represent the most common fungi isolated from the air [2]. Other species are pathogenic to plants and animals, hyperparasites of other fungi, or common epiphytes and endophytes [2-4]. Their environmental plasticity and capacity to establish successful biocenotic interactions are also supported by peculiar biosynthetic capacities, which also make these fungi an interesting source of novel bioactive compounds [5].

The taxonomy of Cladosporium is constantly evolving after recent revisions have pointed out that morphological characters need to be integrated with molecular and ecological data in the attempt to go further into the typification of the many cryptic species which have recently been identified [1,6-9]. More than 230 species are currently recognized in this genus, which is subdivided into three main species complexes: C. cladosporioides, $C$. herbarum and C. sphaerospermum [6]. The assignment of Cladosporium isolates to one of these major species complexes is usually based on morphology or internal transcribed spacers (ITS) sequence analysis [4]. However, phylogenetic reconstructions carried out by using other molecular markers, such as translation elongation factor 1- $\alpha$ (tef1) and actin 1 (act), 
have revealed the species limits of Cladosporium and improved the understanding of the hidden diversity within this genus $[3,10]$.

In Cladosporium, limited insights have been done through DNA-based species delimitation methods, although these tools are recommended as part of an integrative approach to establish well-supported boundaries among fungal species $[9,11]$. These methods use distinct strategies, including genetic distance and coalescence [9], and are increasingly employed in fungal taxonomy [12-14].

We recently examined a set of Cladosporium isolates associated with galled and nongalled flowers of several plants belonging to the Lamiaceae and found it to consist in an assortment of at least 10 species within the C. cladosporioides and C. herbarum species complexes [15]. Two novel species belonging to the first taxonomic group were described, and the existence of a wide genetic variation was observed among the isolates ascribed to the species C. pseudocladosporioides and C. cladosporioides. In particular, the use of two species delimitation methods indicated the possible existence of additional species to be identified within the latter. Defined as the founder of the homonymous species complex, C. cladosporioides is extremely widespread in both terrestrial and marine environments where it is found as a symbiont of many plants and animals in associations ranging from mutualistic to pathogenic $[1,16]$. It also represents the most common Cladosporium species according to the literature and the number of strains having their DNA sequences deposited in GenBank. Based on the provisional evidence resulting in our previous study [15], we decided to more accurately investigate the phylogenetic relationships among the strains of $C$. cladosporioides that have so far been genetically characterized through the deposit in GenBank of sequences of the taxonomic markers ITS, tef1 and act, which are required for molecular delimitation at species level by multilocus approach [2].

We performed phylogenetic and species delimitation analyses aimed at exploring the cryptic diversity of C. cladosporioides. In the course of these analyses, we also assessed intron presence/absence in tef1 sequences, which is considered a feature of phylogenetic importance and often reported as lineage-specific [17]. We analyzed our dataset through different species delimitation methods and placed our trust in delimitations that are congruent across methods. One sequence-based and three tree-based methods were employed that are among the most popular approaches for species delimitation based on sequence data and are frequently used in studies on fungal diversity [12-14,18]: the automatic barcode gap discovery (ABGD) [19], the general mixed Yule-coalescent (GMYC) model [20,21], the Poisson Tree Processes (PTP) [22] and its multi-rate extension (mPTP) [23].

$\mathrm{ABGD}$ is a sequence-based method that sorts the sequences into hypothetical species based on the barcode gap, which can be observed whenever intra-specific is smaller than inter-specific divergence [19]. This is a fast method to split a sequence alignment dataset into candidate species, but its output should be interpreted by complementation with other methods [19]. The GMYC model uses maximum likelihood and an ultrametric gene tree to model the transition between inter- and intraspecific branching patterns [21]. Indeed, this method is based on the prediction that independent evolution leads to the appearance of distinct genetic clusters, separated by longer internal branches in a gene tree [20]. Likewise, PTP tries to determine the transition point from a between- to a within-species process using a two-parameter model, one for the speciation and one for the coalescent process [22]. In contrast to GMYC, PTP estimates branching processes using the expected number of substitutions (vs. time in GMYC) and thus exploits a non-ultrametric phylogenetic tree as input [23]. PTP assumes that every species evolved with the same rate in phylogeny; however, this generally disregards the stochastic variation among species due to different population sizes and demographic histories. Conversely, the recently developed $\mathrm{mPTP}$ fits the branching events of each delimited species to a distinct exponential distribution to account for differences in sampling intensity [23].

To our knowledge, this is the first study that evaluates the performance of several species delimitation methods in Cladosporium and provides a useful framework for combining different analyses aimed at identifying cryptic diversity in fungi. 


\section{Results}

\subsection{Phylogenetic Analysis}

Overall, our analysis included 127 strains (105 of which are reported as C. cladosporioides) and was based on a nucleotide set of $\sim 1400$ bp ( $\sim 690$ bp for ITS, $\sim 490$ bp for tef 1 and $\sim 220 \mathrm{bp}$ for act) (Tables 1 and 2). The resulting alignment revealed the presence of a $\sim 60 \mathrm{bp}$ intron in the tef1 sequence. These isolates formed seven groups with high ML/MP bootstrap support values (82-100), with the majority of them clustering into groups from A to E (Figure 1).

Table 1. A list of Cladosporium cladosporioides isolates that have a complete set of DNA barcode sequences deposited in GenBank.

\begin{tabular}{|c|c|c|c|c|c|}
\hline Code & Source & Country & ITS & tef1 & act \\
\hline AcAv4 & larva of Asphondylia nepetae & Italy & MK387888 & MK416092 & MK416049 \\
\hline AcMt6 & larva of Asphondylia nepetae & Italy & MK387883 & MK416087 & MK416044 \\
\hline AcNa1 & gall on Clinopodium nepeta & Italy & MK387881 & MK416085 & MK416042 \\
\hline AcPp2 & Clinopodium nepeta, receptacle & Italy & MK387885 & MK416089 & MK416046 \\
\hline AcRi7 & Clinopodium nepeta, receptacle & Italy & MK387886 & MK416090 & MK416047 \\
\hline AjNa1 & Ajuga reptans, receptacle & Italy & MK387884 & MK416088 & MK416045 \\
\hline C11G & rice leaf & Brazil & MK049921 & MK073937 & MK073928 \\
\hline C130102 & Fragaria $x$ ananassa & Korea & KJ558398 & KJ558400 & KJ558395 \\
\hline C130110 & Fragaria $x$ ananassa & Korea & KJ558397 & KJ558399 & KJ558394 \\
\hline $\mathrm{C} 18 \mathrm{~Pa}$ & rice leaf & Brazil & MK049923 & MK073939 & MK073930 \\
\hline C19G & rice leaf & Brazil & MK049924 & MK073940 & MK073931 \\
\hline $\mathrm{C} 1 \mathrm{H}$ & rice leaf & Brazil & MK049917 & MK073933 & MK073924 \\
\hline $\mathrm{C} 24 \mathrm{G}$ & rice leaf & Brazil & MK049925 & MK073941 & MK073932 \\
\hline C5G & rice leaf & Brazil & MK049919 & MK073935 & MK073926 \\
\hline CBS 101367 & soil & Brazil & HM148002 & HM148243 & HM148489 \\
\hline CBS $112388^{\dagger}$ & indoor air & Germany & HM148003 & HM148244 & HM148490 \\
\hline CBS 113738 & grape bud & USA & HM148004 & HM148245 & HM148491 \\
\hline CBS 113739 & crested wheat grass & USA & HM148005 & HM148246 & HM148492 \\
\hline CBS 113740 & berry & USA & HM148006 & HM148247 & HM148493 \\
\hline CBS 126341 & spinach seed & USA & HM148009 & HM148250 & HM148496 \\
\hline CBS 143.35 & Pisum sativum & South Africa & HM148011 & HM148252 & HM148498 \\
\hline CBS 144.35 & Pisum sativum & USA & HM148012 & HM148253 & HM148499 \\
\hline CBS 145.35 & Pisum sativum & Germany & HM148013 & HM148254 & HM148500 \\
\hline CBS 674.82 & cotton seed & Israel & HM148014 & HM148255 & HM148501 \\
\hline CDA1 & Phragmidium griseum & Korea & MG451052 & MG451058 & MG451055 \\
\hline CDA2 & Gymnosporangium haraeanum & Korea & MG451053 & MG451059 & MG451056 \\
\hline CDA3 & Gymnosporangium haraeanum & Korea & MG451054 & MG451060 & MG451057 \\
\hline CMG 43 & Fucus spiralis & Portugal & MN053016 & MN066642 & MN066637 \\
\hline COAD 2491 & leaf litter & Brazil & MK253342 & MK293782 & MK249985 \\
\hline COAD 2492 & leaf litter & Brazil & MK253343 & MK293783 & MK249986 \\
\hline CPC 10142 & Chenopodium ficifolium & Korea & HM148015 & HM148256 & HM148502 \\
\hline KUC1384 & Korean pine & Korea & JN033485 & JN033540 & JN033512 \\
\hline CPC 11120 & Viola mandshurica & Korea & HM148017 & HM148258 & HM148504 \\
\hline
\end{tabular}


Table 1. Cont.

\begin{tabular}{|c|c|c|c|c|c|}
\hline Code & Source & Country & ITS & tef1 & act \\
\hline CPC 11121 & Celosia cristata & Korea & HM148018 & HM148259 & HM148505 \\
\hline СРC 11161 & Eucalyptus sp. & India & HM148022 & HM148263 & HM148509 \\
\hline СРС 11363 & Valeriana fauriei & Korea & HM148023 & HM148264 & HM148510 \\
\hline СРС 11398 & rust (Phragmidium griseum) & Korea & HM148024 & HM148265 & HM148511 \\
\hline СРC 11404 & Rubus coreanus & Korea & HM148025 & HM148266 & HM148512 \\
\hline СРC 12187 & Myosoton aquaticum, leaf & Korea & HM148027 & HM148268 & HM148514 \\
\hline CPC 12214 & Morus rubra, leaf & Germany & HM148028 & HM148269 & HM148515 \\
\hline СРC 12760 & Spinacia oleracea, seed & USA & HM148029 & HM148270 & HM148516 \\
\hline СРC 12762 & Spinacia oleracea, seed & USA & HM148030 & HM148271 & HM148517 \\
\hline СРC 12764 & Spinacia oleracea, seed & USA & HM148031 & HM148272 & HM148518 \\
\hline CPC 13667 & Eucalyptus robertsonii & Australia & HM148034 & HM148275 & HM148521 \\
\hline СРС 13669 & Eucalyptus robertsonii & Australia & HM148035 & HM148276 & HM148522 \\
\hline CPC 14015 & wheat & South Africa & HM148038 & HM148279 & HM148525 \\
\hline СРC 14017 & wheat & South Africa & HM148039 & HM148280 & HM148526 \\
\hline CPC 14018 & wheat & South Africa & HM148040 & HM148281 & HM148527 \\
\hline СРC 14019 & wheat & South Africa & HM148041 & HM148282 & HM148528 \\
\hline СРC 14021 & wheat & South Africa & HM148042 & HM148283 & HM148529 \\
\hline СРC 14024 & pawpaw & South Africa & HM148043 & HM148284 & HM148530 \\
\hline СРС 14244 & Magnolia sp. & USA & HM148044 & HM148285 & HM148531 \\
\hline CPC 14271 & twig of unidentified tree & France & HM148045 & HM148286 & HM148532 \\
\hline CPC 14271 & unidentified tree & France & HM148045 & HM148286 & HM148532 \\
\hline CPC 14292 & soil & Denmark & HM148046 & HM148287 & HM148533 \\
\hline CPC 14293 & cellulose powder & Denmark & HM148047 & HM148288 & HM148534 \\
\hline СРC 14355 & mouldy pea & USA & HM148048 & HM148289 & HM148535 \\
\hline СРC 15167 & mite in strawberry leaf & Slovenia & HM148052 & HM148293 & HM148539 \\
\hline CPC 15610 & Rumex sp. & Mexico & KT600385 & KT600482 & KT600580 \\
\hline СРС 15615 & wild tree & Mexico & KT600386 & KT600483 & KT600581 \\
\hline CPC 15626 & wild plant & Mexico & KT600387 & KT600484 & KT600582 \\
\hline CPC 18138 & pine needles & Mexico & KT600388 & KT600485 & KT600583 \\
\hline CPC 18230 & bract of Phaenocoma prolifera & South Africa & JF499834 & JF499872 & JF499878 \\
\hline CPC 22264 & indoor air sample & USA & MF472936 & MF473363 & MF473786 \\
\hline CPC 22265 & indoor air sample & USA & MF472937 & MF473364 & MF473787 \\
\hline СРC 22347 & indoor air sample & USA & MF472938 & MF473365 & MF473788 \\
\hline СРC 22348 & indoor air sample & USA & MF472939 & MF473366 & MF473789 \\
\hline CPC 22365 & indoor air sample & USA & MF472940 & MF473367 & MF473790 \\
\hline СРC 22367 & indoor air & USA & MF472941 & MF473368 & MF473791 \\
\hline CPC 22380 & indoor air sample & USA & MF472942 & MF473369 & MF473792 \\
\hline CRM-AF2 & Vaccinium corymbosum, fruit & Mexico & MN857901 & MN865110 & MN865115 \\
\hline CRM-FF284 & Rubus idaeus, fruit & Mexico & MN857899 & MN865108 & MN865113 \\
\hline CRM-FR283 & Fragaria $x$ ananassa, fruit & Mexico & MN857900 & MN865109 & MN865114 \\
\hline DTO 039-G6 & indoor air sample & Germany & KP701868 & KP701745 & KP701991 \\
\hline
\end{tabular}


Table 1. Cont.

\begin{tabular}{|c|c|c|c|c|c|}
\hline Code & Source & Country & ITS & tef1 & act \\
\hline DTO 071-G1 & indoor air sample & Greece & KP701872 & KP701749 & KP701995 \\
\hline DTO 082-F1 & indoor air sample & The Netherlands & KP701879 & KP701756 & KP702002 \\
\hline DTO 090-C6 & archive & The Netherlands & KР701898 & KP701775 & KP702021 \\
\hline DTO 101-G2 & table & Hungary & MF472943 & MF473370 & MF473793 \\
\hline DTO 101-H7 & floor & Hungary & MF472944 & MF473371 & MF473794 \\
\hline DTO 102-A4 & bathroom & Hungary & KP701905 & KP701782 & KP702028 \\
\hline DTO 109-I4 & indoor environment & Denmark & KP701920 & KP701797 & KP702043 \\
\hline DTO 109-I6 & indoor environment & Denmark & KP701922 & KP701799 & KP702045 \\
\hline DTO 127-D8 & indoor air sample & The Netherlands & KР701933 & KP701810 & KP702055 \\
\hline DTO 147-A9 & indoor environment & Hungary & KP701941 & KP701818 & KP702063 \\
\hline GL0839 & apple & China & JX241647 & JX241672 & JX241674 \\
\hline GZYQ-08-01 & Camellia sinensis, leaf & China & MK852271 & MK852273 & MK852272 \\
\hline GZYQ2018YQX81c & Camellia sinensis, leaf & China & MK799636 & MK799638 & MK799637 \\
\hline KUC1385 & Korean pine & Korea & JN033484 & JN033539 & JN033511 \\
\hline KUC1420 & Japanese red pine lumber & Korea & JN033483 & JN033538 & JN033510 \\
\hline KUC1516 & Korean pine lumber & Korea & JN033479 & JN033534 & JN033506 \\
\hline KUC1545 & Korean pine lumber & Korea & JN033478 & JN033533 & JN033505 \\
\hline KUC1580 & larch & Korea & JN033477 & JN033532 & JN033504 \\
\hline KUC1699 & Japanese red pine & Korea & JN033473 & JN033528 & JN033500 \\
\hline KUC1701 & Japanese red pine & Korea & JN033471 & JN033526 & JN033498 \\
\hline KUC3006 & radiata pine wood & Korea & JN033465 & JN033520 & JN033492 \\
\hline KUC3076 & larch wood & Korea & JN033463 & JN033518 & JN033490 \\
\hline MfCa2 & gall on Micromeria fruticulosa & Italy & MK387882 & MK416086 & MK416043 \\
\hline MFLUCC 170144 & Vitis vinifera & China & MG938710 & MG938823 & MG938675 \\
\hline MFLUCC 170156 & Vitis vinifera & China & MG938711 & MG938824 & MG938676 \\
\hline MFLUCC 170196 & Vitis vinifera & China & MG938712 & MG938825 & MG938677 \\
\hline $\mathrm{MgVi2}$ & larva of Asphondylia sp. & Italy & MK387887 & MK416091 & MK416048 \\
\hline Pelotas1 & Alstroemeria hybrida & Brazil & MG775703 & MG775038 & MG775039 \\
\hline Th/S345 & Thymus vulgaris, achene & Poland & MK387889 & MK416093 & MK416050 \\
\hline UTHSC DI-13-204 & abdomen & USA & LN834358 & LN834454 & LN834542 \\
\hline UTHSC DI-13-209 & pleura & USA & LN834359 & LN834455 & LN834543 \\
\hline UTHSC DI-13-215 & sputum & USA & LN834360 & LN834456 & LN834544 \\
\hline
\end{tabular}

\footnotetext{
${ }^{\dagger}$ Ex-type from neotype of C. cladosporioides.
}

Group A is the largest group, made of 37 isolates, including the neotype CBS 112388 and other strains usually employed as references for this species in phylogenetic studies, besides miscellaneous isolates from diverse locations (Brazil, Europe, Australia, USA and China) and sources (indoor environment, plants and human tissues). Groups B, C, D and $\mathrm{E}$ are closely related to group A but do not include any reference strain. Group B is formed by 14 isolates with different origins (algae from Portugal, rice leaf from Brazil, fruits from South Africa, etc.). Notably, only four of these haplotypes present introns in the tef1 sequence. In group C, there are seven isolates from plants of Korea and India. Isolates in group D have been collected from different geographical and ecological sources (indoor air from the USA, wheat from South Africa, fruits from Mexico, cecidomyid galls 
from Italy, etc.). Interestingly, 16 out of 26 isolates in this group contain introns in the tef1 sequence (Figure 1). Group $\mathrm{E}$ is clearly divergent from the previous groups and only includes two isolates: AjNa1 from the flower of Ajuga reptans in Italy, which was obtained in our previous work [15], and CPC 15626 from an unspecified 'wild' plant in Mexico. Seven out of eight isolates in group F were recovered from conipherous plants in Korea, while one (CBS 674.82) was obtained from cotton seeds in Israel. These isolates cluster together with representatives of the recently described C. anthropophilum [22]. Finally, group $\mathrm{G}$ is formed of two isolates from leaves of Camellia sinensis collected in southwest China and six isolates from Korea associated with several plants and with the Japanese pear rust (Gymnosporangium asiaticum, current name of G. haraeanum). Notably, the phylogram shows that the latter two groups are less closely related to $C$. cladosporioides than to the other species included in the analysis, namely $C$. tenuissimum, $C$. colocasiae, $C$. oxysporum, $C$. vignae, C. angustisporum, C. subuliforme and C. cucumerinum.

Table 2. A list of 22 isolates of Cladosporium species used in the phylogenetic and species delimitation analyses.

\begin{tabular}{|c|c|c|c|c|c|}
\hline Species & Code & Source & ITS & tef1 & act \\
\hline C. angustisporum & CBS 125983 & Alloxylon wickhamii & HM147995 & HM148236 & HM148482 \\
\hline C. angustisporum & DTO-127-E6 & air in bakery & KР701935 & KP701812 & KP702057 \\
\hline C. anthropophilum & CBS 117483 & - & HM148007 & HM148248 & HM148494 \\
\hline C. anthropophilum & CPC 22393 & indoor air & MF472922 & MF473349 & MF473772 \\
\hline C. colocasiae & CBS 386.64 & Colocasia esculenta & HM148067 & HM148310 & HM148555 \\
\hline C. colocasiae & CBS 119542 & Colocasia esculenta & HM148066 & HM148309 & HM148554 \\
\hline C. cucumerinum & CBS 174.62 & painted floor & HM148076 & HM148320 & HM148565 \\
\hline C. cucumerinum & CBS 174.54 & Cucumis sativus & HM148075 & HM148319 & HM148564 \\
\hline C. hillianum & CBS 125988 & leaf of Typha orientalis & HM148097 & HM148341 & HM148586 \\
\hline C. neapolitanum & MgPo1 & Micromeria graeca-receptacle & MK387890 & MK416094 & MK416051 \\
\hline C. neapolitanum & MgVi3 & Micromeria graeca-receptacle & MK387892 & MK416096 & MK416053 \\
\hline C. oxysporum & CBS 125991 & soil & HM148118 & HM148362 & HM148607 \\
\hline C. oxysporum & CBS 126351 & indoor air & HM148119 & HM148363 & HM148608 \\
\hline C. rectoides & CBS 125994 & Vitis flexuosa & HM148193 & HM148438 & HM148683 \\
\hline C. rectoides & CBS 126357 & Plectranthus sp. & MH863933 & HM148439 & HM148684 \\
\hline C. subuliforme & CBS 126500 & Chamaedorea metallica & HM148196 & HM148441 & HM148686 \\
\hline C. subuliforme & DTO-130-H8 & indoor environment & KP701938 & KP701815 & KP702060 \\
\hline C. tenuissimum & XCSY3 & Coriandrum sativum & MG873079 & MT154184 & MT154174 \\
\hline C. tenuissimum & CBS 125995 & Lagerstroemia sp. & HM148197 & HM148442 & HM148687 \\
\hline C. vignae & CBS 121.25 & Vigna unguiculata & HM148227 & HM148473 & HM148718 \\
\hline C. xylophilum & CBS 125997 & dead wood of Picea abies & HM148230 & HM148476 & HM148721 \\
\hline C. xylophilum & CBS 113749 & Prunus avium & HM148228 & HM148474 & HM148719 \\
\hline
\end{tabular}




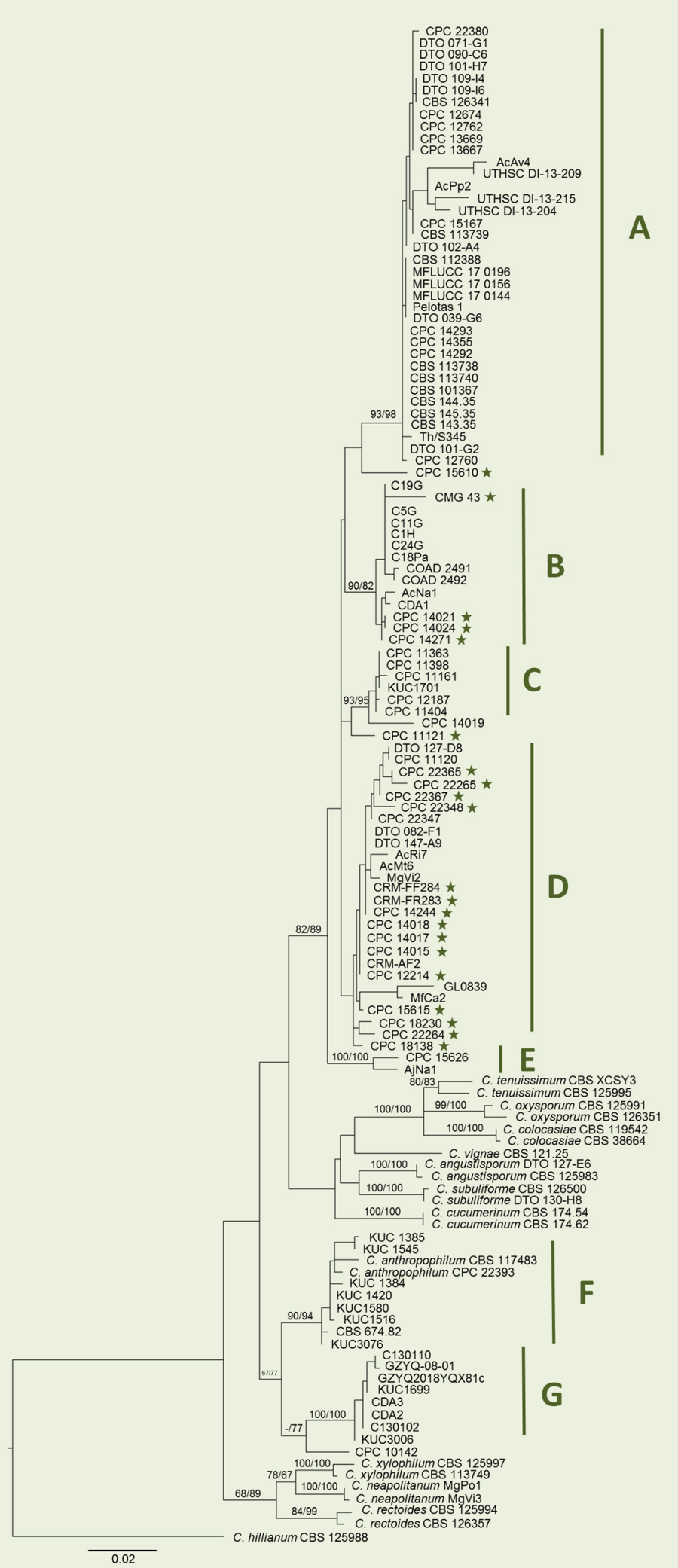

Figure 1. Phylogenetic tree based on maximum likelihood (ML) analysis of combined ITS, tef1 and act sequences of 123 strains from the $C$. cladosporioides complex. Bootstrap support values $\geq 60 \%$ for ML and maximum parsimony (MP) are presented above branches as follows: ML/MP; bootstrap values $<60 \%$ are marked with '-'. C. hillianum CBS 12598 was used as an outgroup reference. Highly supported groups are indicated by letters A, B, C, D, E, F and G. Stars indicate the presence of a $60 \mathrm{bp}$ intron in tef1 sequence. The scale bar indicates the number of nucleotide substitutions per site. 


\subsection{Species Delimitation Analyses}

The same aligned dataset was analyzed using four different species delimitation methods. MPTP was the most conservative method, inferring only four species within $C$. cladosporioides (groups A to E, F and G; Figure 2). ABGD was the second most conservative method, identifying five species, while GMYC and PTP respectively detected 11 and 12 species within C. cladosporioides.

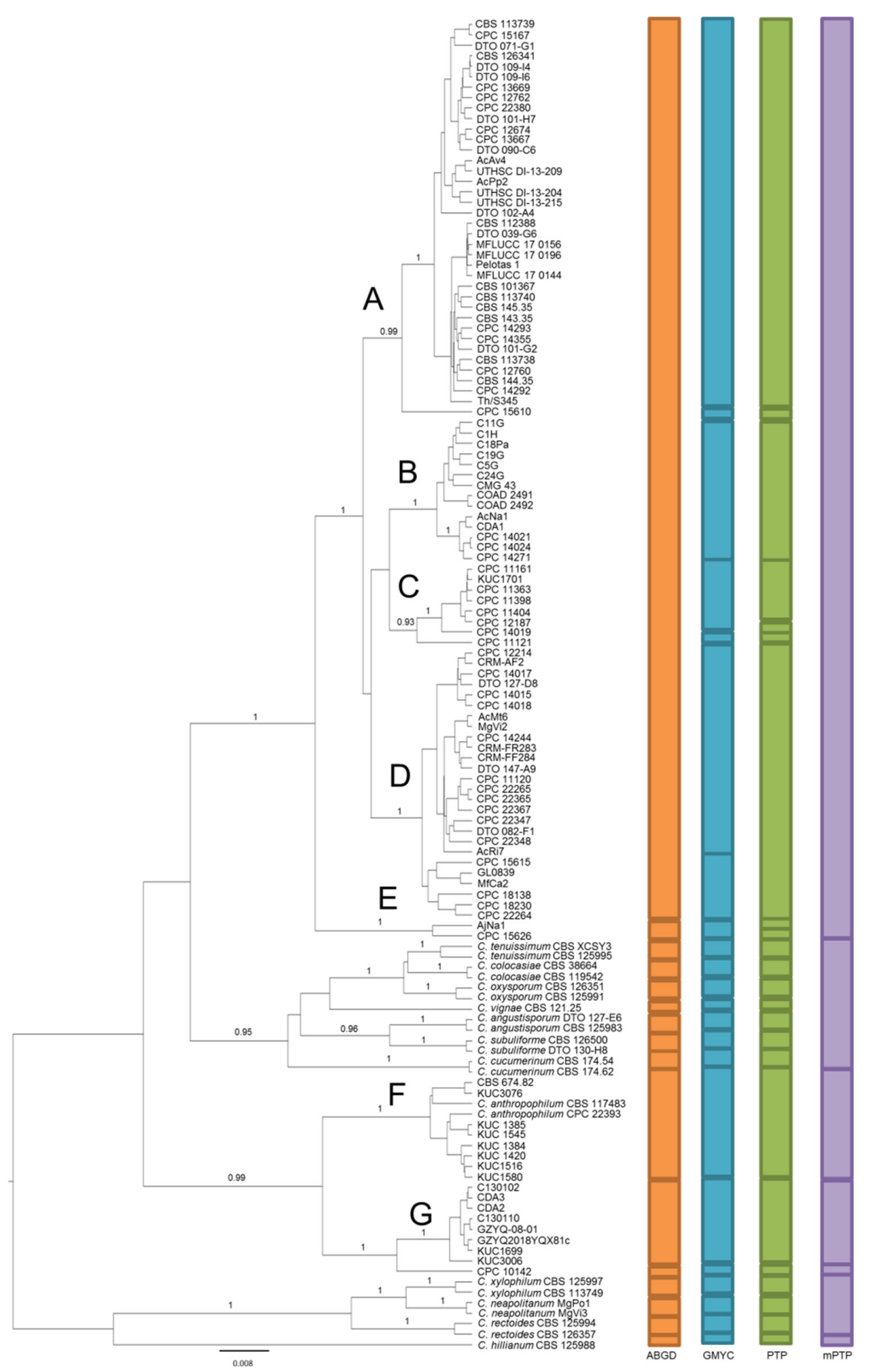

Figure 2. Ultrametric tree phylogeny of $C$. cladosporioides showing the results of the sequence-based species delimitation methods. The tree is the result of a Bayesian analysis performed in BEAST on the concatenated ITS, tef1, act dataset. For each node, posterior probabilities (if $>0.90$ ) are presented above the branch leading to that node. Results of species delimitation analyses are represented by colored boxes to the right. Main groups identified by phylogenetic reconstruction are indicated by letters A, B, C, D, E, F and G. The scale bar represents the substitutions per site according to the model of sequence evolution applied. Different colors indicate the different methods used. 
The tested species delimitation methods correctly identified known species, except for mPTP, which failed to discriminate among C. tenuissimum, C. colocasiae, C. oxysporum, C. vignae, C. angustisporum, C. subuliforme and C. cucumerinum, as well as among C. xylophilum, C. neapolitanum and C. rectoides (Figure 2). The consensus among the remaining methods is high in the lower-middle part of the tree, where group F (C. anthropophilum), group G and the isolate CPC 10142 are indicated as different species (Figure 2). Moreover, isolates AjNa1 and CPC 15626 (group E) are indicated as a single species by ABGD and GMYC, two different species by PTP and grouped together with groups A-D by mPTP. In the upper part of the tree, the methods are discordant, indicating 1 to 7 species for groups $A$ to $\mathrm{D}$, which were pointed out by our phylogenetic reconstruction (Figure 2). The results are very similar between ABGD and $\mathrm{mPTP}$, indicating one species, as well as between GMYC and PTP, which indicated seven species, including the groups A-D (Figure 2).

Overall, the congruence of methods was highest between GMYC and PTP $\left(C_{\operatorname{tax}}=0.87\right)$. The lowest congruence of methods was observed between GMYC and $\operatorname{mPTP}\left(C_{\operatorname{tax}}=0.27\right)$ and between PTP and $\mathrm{mPTP}\left(C_{\mathrm{tax}}=0.28\right)$. Notably, GMYC has the highest mean index of congruence $\left(C_{\operatorname{tax}}=0.62\right)$, while $\mathrm{mPTP}$ has the lowest mean $(0.32)$ (Table 3$)$.

Table 3. Taxonomic index of congruence $\left(C_{\text {tax }}\right)$ for every species delimitation method.

\begin{tabular}{cccccc}
\hline Method & \multicolumn{3}{c}{$C_{\text {tax }}$} & Mean $C_{\text {tax }}$ \\
\hline & ABGD & GMYC & PTP & mPP \\
ABGD & - & - & - & - & 0.60 \\
GMYC & 0.71 & - & - & - & 0.62 \\
PTP & 0.68 & 0.87 & 0.27 & - & 0.60 \\
mPTP & 0.40 & 0.28 & 0.32 \\
\hline
\end{tabular}

$\overline{C_{\text {tax }}}$ index is a measure of congruence in species assignments among two methods, with a value of 1 indicating complete congruence.

\section{Discussion}

In this study, we explored cryptic diversity among C. cladosporioides strains for which ITS, tef1 and act sequences are available in GenBank (last accessed in May 2021), combining phylogenetic and species delimitation analyses. As shown by the phylogenetic tree, the combination of the above-mentioned loci is reliable to distinguish the currently accepted species and indicates with bootstrap support that the isolates recorded in GenBank as C. cladosporioides from seven discrete groups.

Apical groups (A to E) are more closely related to reference strains of C. cladosporioides, while basal groups (F and $\mathrm{G}$ ) are less closely related to C. cladosporioides than to $\mathrm{C}$. tenuissimum, C. colocasiae, C. oxysporum, C. vignae, C. angustisporum, C. subuliforme and C. cucumerinum, suggesting compromised taxonomic annotations. Indeed, group $\mathrm{F}$ includes two strains of $C$. anthropophilum and is consistently reported as a different species by all tested species delimitation methods, as well as group $\mathrm{G}$. The presence in public repositories of mismatches between gene sequences and the species names assigned to the isolates from which they were obtained is frequently reported [24,25] and represents a source of potentially propagating errors [26]. Moreover, the development of new species delimitation methods and the fast growth of the number of described species require more efforts for maintaining and updating public databases [27]. As an example, sequences of CBS 674.82 were uploaded in GenBank in 2010 after it was identified as C. cladosporioides [3], while C. anthropophilum was described for the first time only in 2016 [4].

Our phylogenetic reconstruction pointed out that no clear association can be inferred between plant species, or geographic areas, and group compositions. However, we observed a certain correspondence concerning intron presence in tef1 locus in groups B (28.5\% of the isolates) and D (61.5\% of the isolates), although the presence/absence of the introns in the partial tef1 does not follow the geographical distribution of isolates in contrast to a recently published study on the halotolerant fungus Hortaea werneckii [28]. 
The ultrametric tree obtained through the Bayesian approach shows a highly similar topology to the one depicted by the ML tree, confirming the existence of the same seven groups (A-G). Notably, both tree- (GMYC, PTP) and sequence-based (ABGD) methods are able to correctly distinguish the currently accepted species, also in a context of uneven sampling (i.e., isolates per species ranging from 1 to 105). Surprisingly, the multi-rate extension of PTP (mPTP) cannot discriminate among known species revealing an exaggerated lumping tendency in our conditions. Indeed, this method greatly differs from the others in terms of mean values of the $C_{\operatorname{tax}}$ index, which is a measure of reciprocal congruence between methods, revealing poor delimitation performance for the considered species. These findings are in line with a previous work that suggested that the mPTP method is more conservative than GMYC [25]. Species delimitation analysis unequivocally ascribes groups F and G, as well as the singleton CPC 10142, to different species, with a $100 \%$ consensus among methods. In particular, isolates in group $\mathrm{F}$ are to be ascribed to $C$. anthropophilum, while isolates in group $G$ clearly represent an unknown species. To assess if isolates of group $G$ could eventually be ascribed to a species that is not included in our tree, their sequences of all the tested loci were blasted against GenBank nr database, obtaining only C. cladosporiodes and C. anthropophilum as matches. Hence, considering the output of our species delimitation analyses, these isolates cannot be ascribed to any already described species.

Only a partial match of methods is observed for group E (isolates AjNa1 and CPC 15626). mPTP indicates this group as a single species together with groups A to D; conversely, GMYC and ABGD suggest that group E represents a different species, while PTP identified two separate species. This group is placed at the boundary of C. cladosporioides, as already observed [15], and represents a potential cryptic taxon worth further studies.

A certain discordance among methods is reported for groups A to D. For these groups, the most conservative methods (ABGD and mPTP) indicate one species, while GMYC and PTP indicate seven species. These results are in line with many studies reporting the tendency of ABGD and mPTP to collapse multiple taxa into one [29,30], as well as the tendency of GMYC and PTP to split [23,31].

How can we manage such discordance? Many authors suggest that a conservative approach is preferable to minimize the risk of oversplitting (i.e., the inclusion of false positives) and, thus, delimiting entities that do not represent actual evolutionary lineages [11,32,33]. Other authors suggest the inclusion of an allopatry/sympatry evaluation in order to assess reproductive barriers in a population [34]. However, applying these criteria to fungi can be problematic (e.g., parasites specialized on different sympatric hosts are sometimes considered allopatric) and requires further investigations [35].

Considering that such a high number of species identified by PTP and GMYC is likely the result of the tendency of these approaches to overestimate the number of species, we adopted a conservative strategy consisting of classifying putative species as the most comprehensive groups of isolates predicted by any of the four delimitation methods. Overall, excluding group $\mathrm{F}$, which is ascribed to $C$. anthropophilum, our species delimitation analysis indicates that, following a conservative approach, $C$. cladosporioides isolates available in GenBank have to be grouped at least in two species.

\section{Materials and Methods}

\subsection{Phylogenetic Analysis}

We selected 105 isolates from GenBank reported as C. cladosporioides (Table 1) and 22 isolates ascribed to the 11 most closely related species (C. neapolitanum, C. rectoides, C. xylophilum, C. tenuissimum, C. colocasiae, C. oxysporum, C. vignae, C. angustisporum, C. anthropophilum, C. subuliforme and C. cucumerinum) and to C. hillianum, which was used as the outgroup (Table 2). These species were included in order (1) to provide the taxonomic assignment for C. cladosporioides isolates in the GenBank database and (2) to better fit in the context of species delimitation methods (such as the general mixed Yule-coalescent model), which can be destabilized when less than 5 species are included in the analysis [31]. 
The combined ITS, tef1 and act sequences were aligned by using Muscle [36] and manually adjusted with AliView software version 1.27 [37], where necessary. The aligned sequences were manually checked in order to identify introns, which are frequent in tef1 [17] and are characterized by the presence of GT-AG nucleotides $\left(5^{\prime}-3^{\prime}\right)$. Gaps were treated as missing characters. The phylogenetic analyses were carried out in conformity with recent protocols $[8,38]$. The best nucleotide substitution model (generalized time-reversible model with gamma distribution and a portion of invariable sites $(G T R+G+I)$ for the three independent data sets) was estimated using jModelTest version 2.3 [39] following the Akaike criterion. Phylogenetic analyses of the concatenated sequence data for maximum likelihood (ML) were performed by using RAxML software version 8.2.12 [40] with the GTR $+\mathrm{G}+\mathrm{I}$ model of nucleotide substitution and 1000 bootstrap replications. Concatenated sequences were also analyzed for maximum parsimony (MP) by using PAUP, under the heuristic search parameters with tree bisection reconnection branch swapping, 100 random sequence additions, maxtrees set up to 1000 and 1000 bootstrap. Bayesian analyses were done with a Markov chain Monte Carlo (MCMC) coalescent approach implemented in BEAST v.2.0.2 [41], using the uncorrelated lognormal relaxed clock, the GTR + G + I model, and a coalescent tree prior. Bayesian MCMC was run for 50 million generations, and trees and parameters were sampled every 1000 generations. The resulting log files were entered in Tracer v1.6.0 to check trace plots for convergence and effective sample size (ESS). Burn-in was adjusted to achieve ESS values of $\geq 200$ for the majority of the sampled parameters. While removing a portion of each run as burn-in, log files and trees files were combined in LogCombiner. TreeAnnotator was used to generate consensus trees with $25 \%$ burn-in and to infer the maximum clade credibility tree, with the highest product of individual clade posterior probabilities. Phylogenetic trees were drawn by using FigTree software (tree.bio.ed.ac.uk/software/figtree/, accessed on 12 November 2020).

\subsection{Species Delimitation Analysis}

The ABGD method was tested through a web interface (abgd web, bioinfo.mnhn.fr/ abi/public/abgd/abgdweb.html, accessed on 10 May 2021). Before analysis, the model criteria were set as follows: variability $(P)$ between $0.001(P \min )$ and $0.1(P \max )$, minimum gap width $(\times)$ of 0.1 , Kimura-2-parameters and 50 screening steps. To perform the GMYC delimitation method, an ultrametric tree was constructed in BEAST 2, as described above. After removing 25\% of the trees as burn-in, the remaining trees were used to generate a single summarized tree in TreeAnnotator v.2.0.2 (part of the BEAST v.2.0.2 package) as an input file for GMYC analyses. The GMYC analyses with a single threshold model were performed in R ( $\mathrm{R}$ Development Core Team, www.R-project.org, accessed on 12 May 2021) under the "splits" package using the "gmyc" function (R-Forge, r-forge.rproject.org/projects/splits/, accessed on 9 May 2021). The PTP analysis was carried out with the web service available at http://mPTP.h-its.org (accessed on May 2021) under maximum-likelihood estimations, using both PTP (i.e., using the -single ML option) and mPTP (i.e., using the -multi ML option) model. For PTP/mPTP, we used as input the tree produced with RAxML, as described above, and default settings. Finally, we quantified the performance of methods using the Taxonomic Index of Congruence $\left(C_{\operatorname{tax}}\right)$ [42]. The $C_{\operatorname{tax}}$ index is a measure of congruence in species assignments among two methods, with a value of 1 indicating complete congruence. $C_{\text {tax }}$ metrics were calculated as follows:

$$
C_{\text {tax }}(A B)=\frac{n(A \cap B)}{n(A \cup B)}
$$

where $A \cap B$ represents the number of speciation events shared by methods $A$ and $B$, and $A$ $\cup B$ represents the total number of speciation events inferred by method $A$ and/or $B$ [43].

\section{Conclusions}

Concordance among our results suggests that several strains of C. cladosporioides (group G), isolated in Korea and China, represent a new putative species that requires mor- 
phological characterization prior to formal taxonomic changes. A certain degree of cryptic diversity was observed for group E (isolates AjNa1 and CPC 15626); however, following our conservative approach, this two-membered group cannot be ascribed to a new species without additional molecular, morphological and ecological characterization. Combining in a single analysis several criteria of species delimitation likely brings out discordance among methods, which can be efficiently treated using conservative approaches in order to minimize the risk of considering false positives. Such a promising strategy represents a precious tool for elucidating diversity in directly collected specimens, as well as in public repositories of molecular data.

Moreover, we reported an erroneous taxonomic annotation in GenBank for isolates in group $F$, which should be ascribed to $C$. anthropophilum according to the current taxonomic arrangement. Indeed, data recorded in GenBank require careful examination before being used for taxonomic purposes. Nevertheless, public repositories represent a fundamental resource for studying cryptic diversity using molecular data, which can be viewed as a first step for delineating new taxonomic entities in the highly diverse realm of fungi.

Author Contributions: Conceptualization, B.Z. and R.N.; methodology, A.B.; software, A.B.; formal analysis, A.B.; resources, A.B. and B.Z.; data curation, A.B. and R.N.; writing-original draft preparation, A.B. and R.N.; writing—review and editing, A.B., B.Z. and R.N.; funding acquisition, B.Z. All authors have read and agreed to the published version of the manuscript.

Funding: This research received no external funding.

Institutional Review Board Statement: Not applicable.

Informed Consent Statement: Not applicable.

Data Availability Statement: The data presented in this study are openly available in Zenodo at doi: 10.5281/zenodo.5152222.

Acknowledgments: The contribution by Francesco Pennacchio (Department of Agricultural Sciences, University of Naples Federico II) in the final revision is gratefully acknowledged.

Conflicts of Interest: The authors declare no conflict of interest.

\section{References}

1. Bensch, K.; Groenewald, J.Z.; Braun, U.; Dijksterhuis, J.; de Jesús Yáñez-Morales, M.; Crous, P.W. Common but different: The expanding realm of Cladosporium. Stud. Mycol. 2015, 82, 23-74. [CrossRef]

2. Bensch, K.; Braun, U.; Groenewald, J.Z.; Crous, P.W. The genus Cladosporium. Stud. Mycol. 2012, 72, 1-401. [CrossRef] [PubMed]

3. Bensch, K.; Groenewald, J.Z.; Dijksterhuis, J.; Starink-Willemse, M.; Andersen, B.; Summerell, B.A.; Shin, H.-D.; Dugan, F.M.; Schroers, H.-J.; Braun, U.; et al. Species and ecological diversity within the Cladosporium cladosporioides complex (Davidiellaceae, Capnodiales). Stud. Mycol. 2010, 67, 1-94. [CrossRef] [PubMed]

4. Sandoval-Denis, M.; Gené, J.; Sutton, D.A.; Wiederhold, N.P.; Cano-Lira, J.F.; Guarro, J. New species of Cladosporium associated with human and animal infections. Persoonia 2016, 36, 281-298. [CrossRef]

5. Salvatore, M.M.; Andolfi, A.; Nicoletti, R. The genus Cladosporium: A rich source of diverse and bioactive natural compounds. Molecules 2021, 26, 3959. [CrossRef] [PubMed]

6. Iturrieta-González, I.; García, D.; Gené, J. Novel species of Cladosporium from environmental sources in Spain. MycoKeys 2021, 77, 1-25. [CrossRef] [PubMed]

7. Bensch, K.; Groenewald, J.Z.; Meijer, M.; Dijksterhuis, J.; Jurjević, Ž.; Andersen, B.; Houbraken, J.; Crous, P.W.; Samson, R.A. Cladosporium species in indoor environments. Stud. Mycol. 2018, 89, 177-301. [CrossRef] [PubMed]

8. Sandoval-Denis, M.; Sutton, D.A.; Martin-Vicente, A.; Cano-Lira, J.F.; Wiederhold, N.; Guarro, J.; Gené, J. Cladosporium species recovered from clinical samples in the USA. J. Clin. Microbiol. 2015, 53, 2990-3000. [CrossRef] [PubMed]

9. Maharachchikumbura, S.S.N.; Chen, Y.; Ariyawansa, H.A.; Hyde, K.D.; Haelewaters, D.; Perera, R.H.; Samarakoon, M.C.; Wanasinghe, D.N.; Bustamante, D.E.; Liu, J.-K.; et al. Integrative approaches for species delimitation in Ascomycota. Fungal Divers. 2021. [CrossRef]

10. Haelewaters, D.; Urbina, H.; Brown, S.; Newerth-Henson, S.; Aime, M.C. Isolation and molecular characterization of the romaine lettuce phylloplane mycobiome. J. Fungi 2021, 7, 277. [CrossRef]

11. Carstens, B.C.; Pelletier, T.A.; Reid, N.M.; Satler, J.D. How to fail at species delimitation. Mol. Ecol. 2013, 22, 4369-4383. [CrossRef] 
12. Bustamante, D.E.; Oliva, M.; Leiva, S.; Mendoza, J.E.; Bobadilla, L.; Angulo, G.; Calderon, M.S. Phylogeny and species delimitations in the entomopathogenic genus Beauveria (Hypocreales, Ascomycota), including the description of B. Peruviensis sp. nov. MycoKeys 2019, 58, 47-68. [CrossRef]

13. Haelewaters, D.; De Kesel, A.; Pfister, D.H. Integrative taxonomy reveals hidden species within a common fungal parasite of ladybirds. Sci. Rep. 2018, 8, 15966. [CrossRef]

14. Parnmen, S.; Rangsiruji, A.; Mongkolsuk, P.; Boonpragob, K.; Nutakki, A.; Lumbsch, H.T. Using phylogenetic and coalescent methods to understand the species diversity in the Cladia aggregata complex (Ascomycota, Lecanorales). PLoS ONE 2012, 7, e52245. [CrossRef] [PubMed]

15. Zimowska, B.; Becchimanzi, A.; Krol, E.D.; Furmanczyk, A.; Bensch, K.; Nicoletti, R. New Cladosporium species from normal and galled flowers of Lamiaceae. Pathogens 2021, 10, 369. [CrossRef]

16. AlMatar, M.; Makky, E.A. Cladosporium cladosporioides from the perspectives of medical and biotechnological approaches. 3 Biotech 2015, 6, 4. [CrossRef]

17. Matheny, P.B.; Wang, Z.; Binder, M.; Curtis, J.M.; Lim, Y.W.; Nilsson, R.H.; Hughes, K.W.; Hofstetter, V.; Ammirati, J.F.; Schoch, C.L.; et al. Contributions of Rpb2 and Tef1 to the phylogeny of mushrooms and allies (Basidiomycota, Fungi). Mol. Phylogenet. Evol. 2007, 43, 430-451. [CrossRef]

18. Liu, F.; Wang, M.; Damm, U.; Crous, P.W.; Cai, L. Species boundaries in plant pathogenic fungi: A Colletotrichum case study. BMC Evol. Biol. 2016, 16, 81. [CrossRef] [PubMed]

19. Puillandre, N.; Lambert, A.; Brouillet, S.; Achaz, G. ABGD, Automatic Barcode Gap Discovery for primary species delimitation. Mol. Ecol. 2012, 21, 1864-1877. [CrossRef]

20. Fujisawa, T.; Barraclough, T.G. Delimiting species using single-locus data and the Generalized Mixed Yule Coalescent approach: A revised method and evaluation on simulated data sets. Syst. Biol. 2013, 62, 707-724. [CrossRef]

21. Pons, J.; Barraclough, T.G.; Gomez-Zurita, J.; Cardoso, A.; Duran, D.P.; Hazell, S.; Kamoun, S.; Sumlin, W.D.; Vogler, A.P. Sequence-based species delimitation for the DNA taxonomy of undescribed insects. Syst. Biol. 2006, 55, 595-609. [CrossRef]

22. Zhang, J.; Kapli, P.; Pavlidis, P.; Stamatakis, A. A general species delimitation method with applications to phylogenetic placements. Bioinformatics 2013, 29, 2869-2876. [CrossRef] [PubMed]

23. Kapli, P.; Lutteropp, S.; Zhang, J.; Kobert, K.; Pavlidis, P.; Stamatakis, A.; Flouri, T. Multi-rate poisson tree processes for singlelocus species delimitation under Maximum Likelihood and Markov Chain Monte Carlo. Bioinformatics 2017, 33, 1630-1638. [CrossRef]

24. Nilsson, R.H.; Ryberg, M.; Kristiansson, E.; Abarenkov, K.; Larsson, K.-H.; Kõljalg, U. Taxonomic reliability of DNA sequences in public sequence databases: A fungal perspective. PLoS ONE 2006, 1, e59. [CrossRef]

25. Piemontese, L.; Giovannini, I.; Guidetti, R.; Pellegri, G.; Dioli, P.; Maistrello, L.; Rebecchi, L.; Cesari, M. The species identification problem in mirids (Hemiptera: Heteroptera) highlighted by DNA barcoding and species delimitation studies. Eur. Zool. J. 2020, 87, 310-324. [CrossRef]

26. Leray, M.; Knowlton, N.; Ho, S.-L.; Nguyen, B.N.; Machida, R.J. GenBank is a reliable resource for 21st century biodiversity research. PNAS 2019, 116, 22651-22656. [CrossRef]

27. Lücking, R.; Aime, M.C.; Robbertse, B.; Miller, A.N.; Ariyawansa, H.A.; Aoki, T.; Cardinali, G.; Crous, P.W.; Druzhinina, I.S.; Geiser, D.M.; et al. Unambiguous identification of fungi: Where do we stand and how accurate and precise is fungal DNA barcoding? IMA Fungus 2020, 11, 14. [CrossRef]

28. Marchetta, A.; Gerrits van den Ende, B.; Al-Hatmi, A.M.S.; Hagen, F.; Zalar, P.; Sudhadham, M.; Gunde-Cimerman, N.; Urzì, C.; De Hoog, S.; De Leo, F. Global molecular diversity of the halotolerant fungus Hortaea werneckii. Life 2018, 8, 31. [CrossRef]

29. Huang, W.; Xie, X.; Huo, L.; Liang, X.; Wang, X.; Chen, X. An integrative DNA barcoding framework of ladybird beetles (Coleoptera: Coccinellidae). Sci. Rep. 2020, 10, 10063. [CrossRef]

30. Song, C.; Lin, X.-L.; Wang, Q.; Wang, X.-H. DNA barcodes successfully delimit morphospecies in a superdiverse insect genus. Zool. Scripta 2018, 47, 311-324. [CrossRef]

31. Talavera, G.; Dincă, V.; Vila, R. Factors affecting species delimitations with the GMYC model: Insights from a butterfly survey. Methods Ecol. Evol. 2013, 4, 1101-1110. [CrossRef]

32. Jörger, K.M.; Norenburg, J.L.; Wilson, N.G.; Schrödl, M. Barcoding against a paradox? Combined molecular species delineations reveal multiple cryptic lineages in elusive meiofaunal sea slugs. BMC Evol. Biol. 2012, 12, 245. [CrossRef]

33. Weigand, A.M.; Jochum, A.; Slapnik, R.; Schnitzler, J.; Zarza, E.; Klussmann-Kolb, A. Evolution of microgastropods (Ellobioidea, Carychiidae): Integrating taxonomic, phylogenetic and evolutionary hypotheses. BMC Evol. Biol. 2013, 13, 18. [CrossRef] [PubMed]

34. Kekkonen, M.; Hebert, P.D.N. DNA barcode-based delineation of putative species: Efficient start for taxonomic workflows. Mol. Ecol. Resour. 2014, 14, 706-715. [CrossRef]

35. Giraud, T.; Refrégier, G.; Le Gac, M.; de Vienne, D.M.; Hood, M.E. Speciation in fungi. Fungal Gen. Biol. 2008, 45, 791-802. [CrossRef]

36. Edgar, R.C. MUSCLE: Multiple sequence alignment with high accuracy and high throughput. Nucleic Acids Res. 2004, 32, 1792-1797. [CrossRef]

37. Larsson, A. AliView: A fast and lightweight alignment viewer and editor for large datasets. Bioinformatics 2014, 30, 3276-3278. [CrossRef] 
38. Dissanayake, A. Applied aspects of methods to infer phylogenetic relationships amongst fungi. Mycosphere 2020, 11, 2652-2676. [CrossRef]

39. Darriba, D.; Taboada, G.L.; Doallo, R.; Posada, D. JModelTest 2: More models, new heuristics and high-performance computing. Nat. Methods 2012, 9, 772. [CrossRef] [PubMed]

40. Stamatakis, A. RAxML-VI-HPC: Maximum likelihood-based phylogenetic analyses with thousands of taxa and mixed models. Bioinformatics 2006, 22, 2688-2690. [CrossRef]

41. Bouckaert, R.; Heled, J.; Kühnert, D.; Vaughan, T.; Wu, C.-H.; Xie, D.; Suchard, M.A.; Rambaut, A.; Drummond, A.J. BEAST 2: A software platform for Bayesian evolutionary analysis. PLOS Comput. Biol. 2014, 10, e1003537. [CrossRef]

42. Miralles, A.; Vences, M. New metrics for comparison of taxonomies reveal striking discrepancies among species delimitation methods in Madascincus lizards. PLoS ONE 2013, 8, e68242. [CrossRef]

43. Blair, C.; Bryson, R.W. Cryptic diversity and discordance in single-locus species delimitation methods within horned lizards (Phrynosomatidae: Phrynosoma). Mol. Ecol. Res. 2017, 17, 1168-1182. [CrossRef] 